\title{
Locally applied simvastatin promotes fracture healing in ovariectomized rat: a novel molecular mechanism
}

\author{
H. Namazi
}

Received: 11 February 2008 / Accepted: 13 March 2008 / Published online: 18 April 2008

(C) International Osteoporosis Foundation and National Osteoporosis Foundation 2008

Dear Editors,

I read with great interest the article by Wang and colleagues [1].

This work shows that simvastatin markedly promotes fracture healing compared with a placebo. I would like to complete the discussion of Wang and coworkers [1] by introducing a major route through which simvastatin could promote healing.

Diminished bone formation during fracture healing is related to the premature resorption of callus associated with increased osteoclast activity. The osteoclastic cells, which cause impaired healing, are thought to be recruited from normal monocytic pre-osteoclasts by stromal cell expression of the ligand for receptor activator of nuclear factor kappaB (RANKL). RANKL is an osteoclastogenesis factor released by osteoblasts, stromal cells, and activated T cells. RANK is a receptor that is present on the cell membrane of osteoclasts, monocytes, and osteoblasts [2, 3]. Studies have shown the role of RANKL in delay union as evidenced by the inhibitory effect of osteoprotegerin (a decoy receptor of RANKL) on RANKL-mediated osteoclastogenesis [4, 5].

Fusion of the cell membrane of mononuclear preosteoclasts is a critical initial step in osteoclast maturation. Cholesterol in the membranes of monocytes is involved in the osteoclast-like cell formation via cellular membrane fusion events. The addition of native LDL cholesterol increases osteoclast viability by suppressing spontaneous apoptosis, while cholesterol removal strongly induces

H. Namazi $(\bowtie)$

Department of Orthopaedic Surgery,

Shiraz University of Medical Sciences,

Shiraz, Iran

e-mail: Namazih@sums.ac.ir

H. Namazi

Chamran Hospital,

Shiraz, Iran apoptosis in osteoclast. Moreover, cholesterol removal by HDL, apolipoprotein A1 (ApoA1) or methyl- $\beta$-cyclodextrin (MBCD) triggers induction of apoptosis and OCL death. Cholesterol in the cell membrane is derived from de novo synthesis via HMG-CoA reductase [6, 7].

Simvastatin (HMG-CoA reductase inhibitor) is a hypolipidemic drug belonging to the class of pharmaceuticals called statins. Also, data obtained in recent studies have demonstrated that simvastatin stimulate the OPG production by osteoblasts which can lead to a significant reduction in RANKL [8]. Therefore, these important mechanisms should be borne in mind as the major mechanisms for simvastatininduced healing.

\section{References}

1. Wang JW, Xu SW, Yang DS et al (2007) Locally applied simvastatin promotes fracture healing in ovariectomized rat. Osteoporos Int 18 (12):1641-1650 DOI 10.1007/s00198-007-0412-2

2. Fan W, Crawford R, Xiao Y (2008) Structural and cellular differences between metaphyseal and diaphyseal periosteum in different aged rats. Bone 42(1):81-89

3. Davies JE (2007) Bone bonding at natural and biomaterial surfaces. Biomaterials 28(34):5058-5067

4. Tang L, Lin Z, Li YM (2006) Effects of different magnitudes of mechanical strain on osteoblasts in vitro. Biochem Biophys Res Commun 344(1):122-128

5. Rogers A, Eastell R (2005) Circulating osteoprotegerin and receptor activator for nuclear factor kappaB ligand: clinical utility in metabolic bone disease assessment. J Clin Endocrinol Metab 90 (11):6323-6331

6. Whitfield JF (2003) How to grow bone to treat osteoporosis and mend fractures. Curr Rheumatol Rep 5(1):45-56

7. Edwards CJ, Spector TD (2002) Statins as modulators of bone formation. Arthritis Res 4(3):151-153

8. Kaji H, Kanatani M, Sugimoto T et al (2005) Statins modulate the levels of osteoprotegerin/receptor activator of NFkappaB ligand mRNA in mouse bone-cell cultures. Horm Metab Res 37(10): 589-592 